\title{
Prevalence of Human Papillomavirus (HPV) Genotypes and Multiple Infections in Routine Cervical Cancer Screening in a Spanish Regional Population
}

\author{
Morelva Toro de Mendez* \\ Universidad de Los Andes, Merida, Venezuela
}

Received: November 23, 2013; Accepted: December 12, 2013; Published: December 16, 2013

*Corresponding author: Morelva Toro de Mendez, Universidad de Los Andes, Merida, Venezuela, Tel: 0058-4147346547; E-mail: tmorelva@ula.ve

\begin{abstract}
Background: Infection with human papillomavirus (HPV) has been identified as the primary cause of cervical cancer. Persistent infection with high risk-HPV is the required factor for the development of cervical cancer.

Objective: The aim of this study was to know the prevalence and distribution of cervical HPV infection in women attending routine cervical cancer screening.

Study design: Liquid-based cytology (LBC) of cervical specimens was processed for HPV testing by INNO-LiPA HPV genotyping Extra Reverse Hybridization Line Probe Assay kit.

Results: The cytological results of 115 LBCs were: $11(9.6 \%)$ negative for intraepithelial lesion or malignancy (NILM), 32(27.8\%) atypical squamous cells of undetermined significance (ASC-US), 62(53.9\%) low-grade squamous intraepithelial lesion (LSIL) and $10(8.7 \%)$ high-grade squamous intraepithelial lesion (HSIL). No cases of cervical cancer were detected. The mean age was 33.78 years \pm 10.75 years (range 17-62 years). The overall prevalence DNA HPV detection was $81.7 \%(94 / 115)$, with a large proportion of multiple HPV infection (55.0\%). HPV16 was the most common type detected (8.7\%) followed by HPV51 (7.8\%), HPV52 (5.2\%), and HPV66 (2.6\%). We found a high proportion of HPV positive cases in all cytological categories, including NLIM cases.
\end{abstract}

Conclusions: These results indicate that prevalence of HPV infection in women attending routine cervical cancer screening is high. Our results confirm the importance of identifying the types of HPV that affect this community to design more effective prevention strategies and thus contribute to the fight against cervical cancer and its precursor lesions.

Keywords: Liquid-based cytology; Screening cervical cancer; Prevalence; HPV; Multiple HPV infection.

\section{Background}

Cervical cancer is the second most common cancer in women worldwide and the most common cause of mortality in underdeveloped and developing countries [1,2]. Persistent infection with certain oncogenic high-risk (HR) types of Human Papillomavirus (HPV) is the required factor for the development of invasive cervical cancer and precursor lesions [3-6].
Overall, the prevalence and distribution of HPV infection in cervical lesions has been determined in many geographical regions of the world, this can vary depending on several factors including epidemiological differences in the populations studied and the methodology used for molecular detection and typing of HPV DNA [7]. Over 120 types of HPV have been classified as either low (LR-HPV) or high risk (HR-HPV), according to their oncogenic potential $[8,9]$. Within the high-risk genotypes, HPV types 16 and HPV 18 are most often associated with cancer and squamous intraepithelial lesion $[5,6,10,11,12]$. Nevertheless, the risk of neoplasia for other types of HPV as well as for multiple HPV infection has not yet been established.

Because currentstrategies for the prevention of cervical cancer and their precancerous lesions are based on the HPV genotyping [13] and prophylactic vaccines [14-16], it seems necessary to determine the types of HPV most commonly associated with malignant cell transformation in different geographical areas in order to establish effective preventive measures according to the epidemiology of the population. This study was to know the prevalence and distribution of cervical HPV infection in women attending routine cervical cancer screening in the Valencia region (Spain).

\section{Study design}

Liquid-based cytology (LBC) of cervical specimens was collected during routine screening visits, between June 20, 2011 and September 9, 2011 in the Clinical Hospital of Valencia, Spain. LBC samples were processed using the Thin Prep® 5000 processor (Madrid, Spain). For HPV detection and genotyping, we used the residual cervical sample material available from the same Thin Prep Pap test vial previously used for cytological screening. DNA was extracted from the residual materials of LBC by QIAamp® DNA mini kit (IZASA, Valencia, Spain), according to the manufacturer's instructions. HPV testing was performed by INNO-Lipa HPV genotyping Extra Reverse Hybridization Line Probe Assay kit (Innogenetics $\AA$, Barcelona, Spain), according to the manufacturer's instructions. Briefly, HPV detection and genotyping was based on PCR amplification of a $65 \mathrm{pb}$ fragment, within the L1 region of the HPV genome, using broad-spectrum SPF10 biotinylated primers. PCR was performed in a final 
reaction volume of $50 \mu \mathrm{l}$ containing $40 \mu \mathrm{l}$ of PCR master mix and $10 \mu \mathrm{l}$ of the extracted DNA. The amplification programme took 9 min at $94^{\circ} \mathrm{C}$ followed by $94^{\circ} \mathrm{C}$ for $30 \mathrm{sec}, 52^{\circ} \mathrm{C}$ for $45 \mathrm{sec}$ and $72^{\circ} \mathrm{C}$ for $45 \mathrm{sec}$ for a total of 40 cycles, with a final extension of $10 \mathrm{~min}$ at $72^{\circ} \mathrm{C}$. For hybridization, we used the AutoBlot $3000 \mathrm{H}$ INNOLiPA HPV genotyping Extra procedure (Innogenetics, Barcelona, Spain), according to manufacturer's instructions. The LIRAS ${ }^{\circledR}$ (Innogenetics, Barcelona. Spain) for LiPA HPV software was designed to assist with genotyping extra results. The samples for which the obtained line pattern could not be assigned to any genotype pattern or which had no type-specific lines, but had a least one HPV control line positive were considered HPV-positive but undetermined (HPVX).

\section{Statistical analysis}

Statistical analysis was performed with the SPSS v17.0 statistical package. A p value of 0.05 or less was considered statistically significant.

\section{Results}

A total of 115 liquid-based cervical cytology were included in this study: $11(9.6 \%)$ were negative for intraepithelial lesion or malignancy (NILM), 32(27.8\%) were atypical squamous cells of undetermined significance (ASC-US), 62(53.9\%) were low-grade squamous intraepithelial lesions (LSIL), and 10(8.7\%) highgrade squamous intraepithelial lesions (HSIL). No case of cervical cancer was diagnosed. The mean age was 33.8 years (standard deviation, 10.75) and age range 17-62 years.

The cases were divided into two age groups $<40$ and $\geq 40$ years. The major proportion of cases studied $(70.2 \%)$ belonged to patients $<40$ years, while $29.8 \%$ were $\geq 40$ years. $90.4 \%$ of cases (103/115) had abnormal Pap smears (ASC-US, LSIL and HSIL) distributed irrespective of age $(p=0.078)$, however, $73 / 103$ $(64.0 \%)$ were $<40$ years.

94 out of 115 cervical specimens were HPV DNA positive (81.7\%). The highest proportion of positive HPV cases (60.5\%) corresponded to patients younger than 40 years. $21.1 \%$ of patients $\geq 40$ years also had viral infection with statistically significant differences $(\mathrm{p}=0.048)$.

Among the HPV positive specimens, $45.0 \%$ (42/94) was identified as single HPV types and $55.0 \%$ with multiple HPV types, with statistically significant differences $(\mathrm{p}<0.001)$. At least one high-risk HPV genotype was detected in the samples with HPV co-infection. The four most common single types among positive cases were: 10 HPV16 (8.7\%), 9 HPV51 (7.8\%), 6 HPV52 (5.2\%), and 3 HPV66 (2.6\%). Also 10 undetermined HPV (HPVX) were positive cases (8.7\%). HPV16 was present in 20.9\% of HPVpositive samples, including single and multiple HPV infection (Table 1). The most frequent viral types in this study were HR-HPV. Few LR-HPV types were found in the oncogenic cases studied. The most frequent virus type was HPV16, both as single or multiple. HPV18 was rare. Types HPV31 and HPV33 were frequent in multiple infections cases. Types HPV-51, -52 and -66 were very common in single and multiple infections, combined with other HR-HPV types. HPVX was often present in the form of single infection and was present in 9 cases of coinfection (Table

\begin{tabular}{|c|c|}
\hline HPV genotypes & Frequency (percentage) \\
\hline HPV negative & $21(18.3 \%)$ \\
\hline HPV positive & $94(81.7 \%)$ \\
\hline 11 & $1(0.9 \%)$ \\
\hline 16 & $10(8.7 \%)$ \\
\hline 35 & $1(0.9 \%)$ \\
\hline 39 & $1(0.9 \%)$ \\
\hline 51 & $9(7.8 \%)$ \\
\hline 52 & $6(5.2 \%)$ \\
\hline 58 & $1(0.9 \%)$ \\
\hline 66 & $3(2.6 \%)$ \\
\hline $16-51$ & $1(0.9 \%)$ \\
\hline $16-52$ & $1(0.9 \%)$ \\
\hline $16-53$ & $1(0.9 \%)$ \\
\hline $16-66$ & $1(0.9 \%)$ \\
\hline $16-74$ & $1(0.9 \%)$ \\
\hline $18-39$ & $3(2.6 \%)$ \\
\hline $45-52$ & $1(0.9 \%)$ \\
\hline $45-66$ & $1(0.9 \%)$ \\
\hline $51-52$ & $1(0.9 \%)$ \\
\hline $51-53$ & $1(0.9 \%)$ \\
\hline $51-66$ & $1(0.9 \%)$ \\
\hline $52-66$ & $3(2.6 \%)$ \\
\hline $56-74$ & $3(2.6 \%)$ \\
\hline $58-52$ & $1(0.9 \%)$ \\
\hline $11-16-52$ & $1(0.9 \%)$ \\
\hline $11-51-66$ & $1(0.9 \%)$ \\
\hline $11-52-X$ & $1(0.9 \%)$ \\
\hline $11-66-X$ & $1(0.9 \%)$ \\
\hline $16-31-33$ & $1(0.9 \%)$ \\
\hline $16-31-52$ & $2(1.7 \%)$ \\
\hline $16-39-53$ & $1(0.9 \%)$ \\
\hline $16-51-52$ & $2(1.7 \%)$ \\
\hline $16-51-53$ & $1(0.9 \%)$ \\
\hline $16-51-58$ & $1(0.9 \%)$ \\
\hline $16-69-71$ & $1(0.9 \%)$ \\
\hline $16-X$ & $1(0.9 \%)$ \\
\hline $18-31-51$ & $1(0.9 \%)$ \\
\hline $18-51-39$ & $1(0.9 \%)$ \\
\hline $31-52-54$ & $2(1.7 \%)$ \\
\hline $33-39-66$ & $1(0.9 \%)$ \\
\hline $33-52-54$ & $1(0.9 \%)$ \\
\hline $33-52-X$ & $1(0.9 \%)$ \\
\hline $35-51-52$ & $1(0.9 \%)$ \\
\hline $39-51-53$ & $1(0.9 \%)$ \\
\hline 39-51-69 & $1(0.9 \%)$ \\
\hline $39-58-26$ & $1(0.9 \%)$ \\
\hline $39-82-X$ & $1(0.9 \%)$ \\
\hline $52-53-74$ & $1(0.9 \%)$ \\
\hline $52-66-74$ & $1(0.9 \%)$ \\
\hline $52-X$ & $1(0.9 \%)$ \\
\hline 53-52-X & $1(0.9 \%)$ \\
\hline $54-X$ & $1(0.9 \%)$ \\
\hline $6-X$ & $1(0.9 \%)$ \\
\hline $\mathrm{X}$ & $10(8.7 \%)$ \\
\hline Total & $115(100 \%)$ \\
\hline
\end{tabular}

HPV: human papillomavirus. X: undetermined HPV.

Table 1: HPV testing and typing in cervical specimens. 
1). HPV39 was frequently found in combination with other HPVs. HPV11 was the most common LR-HPV type.

$28.1 \%$ of cases in the $<40$ years group were infected by one HPV type, as well as $8.8 \%$ of women $\geq 40$ years. Multiple infection was detected in $32.5 \%(37 / 80)$ women $<40$ years and decreased with age, $12.3 \%(14 / 34)$, without statistically significant differences $(\mathrm{p}=0.133)$.

We found a high proportion of HPV positive cases in all cytological categories, including NLIM cases (Table 2). The distribution of HPV positivity between cytological categories is shown in Figure 1. Thirty-eight cases of LSIL (33.0\%) had multiple HPV infection, followed by 8 ASC-US (7.0\%), while only $6.1 \%$ of HSIL were infected. Multiple HPV infection was more common in LSIL and ASC-US, while single HPV infection was more frequent in HSIL.

\section{Discussion}

At present, it is very important to know the distribution of other types of HPV that enhance or decrease the risk of developing cervical neoplasia. The distribution of HPV types in cervical lesions is crucial to the design of second-generation prophylactic vaccines effective for specific populations.

In Spain, crude prevalence rates for HPV infection in small, specific populations or in limited geographical areas have been previously reported to range from $3 \%$ to $17 \%$ [17-20]. In a study to provide specific information for Spain in 1,043 histologically confirmed invasive cervical cancer cases from six regions, 904 of these cases (89.1\%) were HPV DNA positive [5]. In this study, a high prevalence of HPV infection (81.7\%) as well as a high diversity of oncogenic HPV types was observed. This proportion is equivalent to that found in abnormal Pap tests from a populationbased screening program [21], in HIV-positive Brazilian women [22] and in a study of worldwide HPV genotype distribution in cervical cancer [12]. While HPV infection was detected in $98.4 \%$ of women with histologically confirmed CIN2 or higher [23]. The presence of cervical lesions in the populations studied could be the reason for the similarity in the prevalence of HPV infection.

The high prevalence of HPV infection is common in young women $[6,24,25]$. In all geographical regions, HPV prevalence was highest in women younger than 35 years of age, decreasing

\begin{tabular}{|c|c|c|}
\hline \multirow{2}{*}{ Cytological findings } & \multicolumn{2}{|c|}{ HPV } \\
\cline { 2 - 3 } & Negative & positive \\
\hline NILM $(\mathrm{n}=11)$ & $2(18.0 \%)$ & $9(81.8 \%)$ \\
\hline ASC-US $(\mathrm{n}=32)$ & $14(44.0 \%)$ & $18(56.0 \%)$ \\
\hline LSIL (n=62) & $4(6.5 \%)$ & $58(93.5 \%)$ \\
\hline HSIL (n=10) & $1(10.0 \%)$ & $9(90.0 \%)$ \\
\hline Total $(\mathrm{n}=115)$ & $\mathbf{2 1 ( 1 8 . 3 \% )}$ & $\mathbf{9 4}(\mathbf{8 1 . 7 \% )}$ \\
\hline
\end{tabular}

NILM: negative for intraepithelial lesion or malignancy. ASC-US: atypical squamous cells of undetermined significance. LSIL: low-grade squamous intraepithelial lesion. HSIL: high-grade squamous intraepithelial lesion. HPV: human papillomavirus

Table 2: Distribution of HPV detection results according to cytological findings.

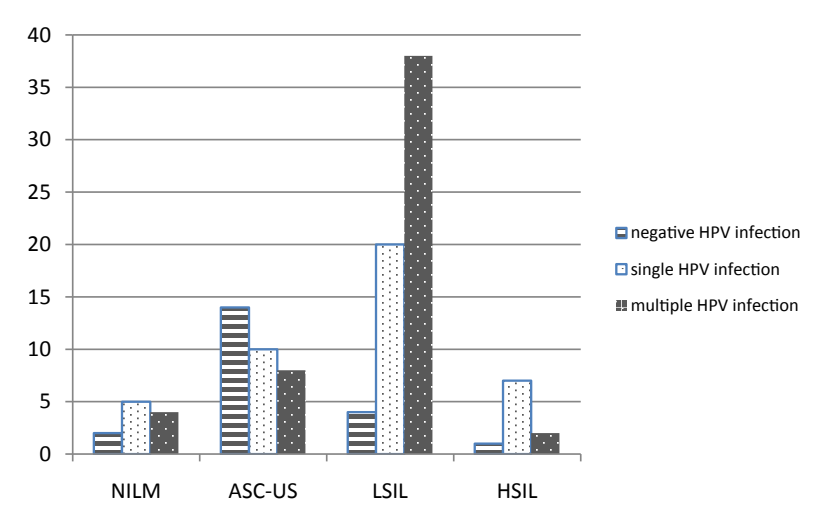

Figure 1: Cytological findings and distribution of detection HPV results.

in older women [26]. Regarding age distribution, $69 \%$ of all HPV infections were found in women aged $20-29$ years $[27,28]$.

In this study, the prevalence of HPV (81.7\%) of women living in this Spanish region was higher than that observed in Spanish data published previously among women aged 18-65 years (14.3\%) and women aged 18-25 years (28.8\%) [6]. Furthermore, we found highest prevalence of HPV $(60.5 \%)$ in patients $<40$ years, even higher than that reported in other studies carried out in Spanish women, probably because it encompasses a different age group [6]. In previous studies conducted in this same context, HPV infection was positive in $90 \%$ of the patients with abnormal cytology and a mean age of 40 years [29], and in $43.3 \%$ in patients with mean age of 40.9 years of the routine screening [30].

The distribution of HPV genotypes and prevalence estimates are dependent on population characteristics such as age, sexual behavior, severity of cervical disease, and the geographic location of the patients as well as of the method(s) of detection and indicate that suboptimal analytical sensitivity for one or more of the less common HR-HPV genotypes could lead to impaired clinical sensitivity $[6,10,31-33]$

In this study we found a high prevalence of HPV infection in cases with normal cytological findings (NILM). This high prevalence suggests that it belongs to an epidemiologically relevant population, which should be monitored in order to prevent the occurrence of HSIL or cancer. The study also allows the monitoring of the evolution of the viral infection, and the role of synergism between HPVs involved in the development of cervical neoplasia. Overall HPV prevalence in 157,879 women with normal cervical cytology was estimated to be $10.4 \%$ [26]. In Spain, about $13 \%$ of NILM cases are HPV positive [6]. The present findings confirm the very high prevalence of HPV infection in patients with normal cytology of this area of Spain [30].

The distribution of HPV genotypes in this study was consistent with that reported in studies previously [20,29,30,34]. HPV16 has been consistently identified as the most frequent HR-HPV. Other HR-HPV types have also been frequently detected. The more common HR-HPV genotypes prevalent in the CLEOPATRE study ${ }^{6}$ were HPV-16, $-51,-52$ and -66 , which were also present in this study. HPV16 was detected in $16.9 \%$ of samples of the 
CLEOPATRE study, while in this present study it was positive in $20.9 \%$ of cases.

While the role for some HPV types, such as HPV16 and HPV18 in carcinogenesis cervical is well established, the role of other HPV types is less clear. In this study, HPV-51 (7.8\%), -52 $(5.2 \%)$ and $-66(2.6 \%)$ were detected. These viral types appear to be common in the Spanish population [6,18,35-38], and these HPV specific-genotypes were also detected in studies around the world. The proportions detected in these studies are diverse, being as high as $17.5 \%, 12.0 \%$, and $8.1 \%$ respectively [35], while in other study [38] found similar rates to those of our study: $8.0 \%, 3.8 \%$, and $7.1 \%$, respectively. Very low proportions have also been detected, such as $1.6 \%, 1.8 \%$, and $1.2 \%$, respectively [6], and HPV-51 (0.75\%), HPV-52 (2.25\%) and HPV-66 (0.19\%) [10]. Finally, considering the study which was estimated the prevalence of HR-HPV in Latin American immigrants in Spain finding a high prevalence of HPV51 (13.0\%) and HPV66 (27.0\%) [18], and that Valencia is a cosmopolitan city, with a large population of immigrants, it is also important to take these findings into account when designing future preventive strategies [10]. These types of HPV are of interest after Fife et al. [39] suggested that those viruses might cooperate with HPH16 in the development of cancer. Therefore, the HPV-51, -52, and -66 genotypes should be considered in future research to determine the true prevalence and contribution in the progress of HSIL to cervical cancer $[40,41]$.

Interestingly, in this study a high prevalence of undetermined HPV (HPV X) was found (8.7\%). Other studies in which the LiPA method was used for typing of HPV have found a prevalence of $8.3 \%$ of HPVX in women with histopathologically confirmed cervical lesions [42], in $2.2 \%$ of women diagnosed with cervical lesions [43], and 1.0\% in cervical cancer cases [12]. Rabelo-Santos et al. [44] who used the dot blot hybridization method found $6 \%$ of HPVX, and Castellsague et al. [6], who used exactly the same method as in this study, found $3.8 \%$ of HPVX. Nevertheless, the HPVX prevalence established by Goncalves et al. [22] in comparison with our and other studies was very high (18.7\%). Considering the high prevalence of HPVX in this environment, it is recommended to separate these cases and submit them to sequencing for correct identification, evaluation of the degree of oncogenicity, and consideration for prophylactic vaccines.

Coinfection with multiple HPV types is common in younger women with cervical lesions and a poor immune response. Multiple HPV infections could be a clinically important finding, although the significance of infection with multiple HPV types in cervical carcinogenesis process is not known [45-49]. Multiple HPV infections are common in women with ASC-US and LSIL. The ALTS study 2000 [50] found that $58.9 \%$ of the subjects with LSIL had between two and six different HPV types. Prevalence of HPV infection depends on the age of the study population [51]. In women aged below 30 years, there was a predominance of multiple infections and ASC-US/LSIL was associated with multiple infection and HSIL with single infections [36].

Multiple HPV infections decrease with severity of lesion, being less frequent in HSIL [34], a fact that coincides with the present findings. However, in a study of 298 women with abnormal cervical cytology in Kuwait [27], reported that as the severity of the cytological diagnosis increased the proportion of single infections decreased, while the proportion of multiple infections increased, and Fife et al. [39] found $85.3 \%$ of multiple HPV infections in dysplasia and 61.9\% in ASC-US, these last concluding that their data support a possible role for multiple HPV types in the development or progression of cervical dysplasia. This is an issue that requires further investigation.

In this study, $55.0 \%$ of cases were positive for multiple HPV infections being more frequent in cases of LSIL [52,53]. The prevalence of multiple HPV infection has been reported in a range that varies from $54.0 \%$ to $78.9 \%$ [21,46,54-56]. Our results fall within this range. This prevalence of multiple HPV infection is higher than found in other studies conducted in Spain in which the values range between $4.7 \%$ and $52.1 \%[6,29,30,34,36,38,57]$. Furthermore, in a study of patients with abnormal cytology obtained a higher value (58.1\%) [35] than found in this study. The variations observed could be explained by the geographical diversity of the population studied [58] and the different molecular methodologies used. Most of these studies, including ours, used highly sensitive molecular technology designed to reach a large number of specific HPV genotypes. The incorporation of highly sensitive and specific molecular methodology in screening for cervical cancer and typing of HPV could explain why-increasingly more cases of coinfection with several types of HPV are detected $[10,22,59]$.

In conclusion, the infection with multiple HPV types is frequent in women attending routine cervical cancer screening. We found a high proportion of HPV positive cases, even in cytological NILM cases. Multiple HPV infection is very common in patients with normal and abnormal Pap smears. There is a diversity of HPV types, and HPV16 remains the most common type both in patients with normal and abnormal cytology. The true prevalence of HPV types-51, -52 and -66 , as well as the identity of HPVX remains unknown, therefore it seems necessary to pursue studies in order to establish their oncogenicity. Our results confirm the importance of recognizing the types of HPV in women of Valencia to design more effective prevention strategies and thus contribute to improving the fight against cervical cancer and its precursor lesions.

\section{Acknowledgments}

We thank the staff of the Pathology Department of the University of Valencia and the Anatomical Pathology Service of the Clinical Hospital of Valencia, especially Alejo Sempere, Richart Sotos and Amparo Duet.

\section{Funding}

The study was supported by the Junta Provincial of the AECC, Valencia, Spain.

\section{Contributors}

AFI and ALB participated in the study design and interpretation of the results. MTM participated in data collection and analysis, interpretation of the results, and writing the report. All authors provided approval of the final draft of the report. 


\section{References}

1. International Agency for Research on Cancer, WHO. CI5: Cancer Incidence in Five Continents. Cited 2013 Aug 22, Accessed at http:// ci5.iarc.fr/Default.aspx

2. WHO/ICO (2010) Information centre on HPV and cervical cancer (HPV Information centre). Human papilloma virus and related cancers. Summary report update.

3. Walboomers JM, Jacobs MV, Manos MM, Bosch FX, Kummer JA, et al. (1999). Human papillomavirus is a necessary cause of invasive cervical cancer worldwide. J Pathol 189(1): 12-19.

4. zur Hausen H (2002) Papillomaviruses and cancer: from basic studies to clinical application. Nat Rev Cancer 2(5): 342-350.

5. Alemany L, Perez C, Tous S, Llombart-Bosch A, Lloveras B, et al (2011) Spanish study group RIS HPV TT. Human papillomavirus genotype distribution in cervical cancer cases in Spain. Implications for prevention Gynecol Oncol 124(3): 512-517.

6. Castellsague X, Iftner T, Roura E, Vidart JA, Kjaer SK, et al. (2012) Prevalence and genotype distribution of human papillomavirus infection of the cervix in Spain: the CLEOPATRE study. J Med Virol 84(6): 947-956.

7. Rousseau MC, Pereira JS, Prado JC, Villa LL, Rohan TE, et al. (2001) Cervical coinfection with human papillomavirus (HPV) types as a predictor of acquisition and persistence of HPV infection. J Infect Dis 184(12): 1508-1517.

8. Munoz N, Bosch FX, de Sanjose S, Herrero R, Castellsague X, et al. (2003) International Agency for Research on Cancer Multicenter Cervical Cancer Study Group. Epidemiologic classification of human papillomavirus types associated with cervical cancer. N Engl J Med 348: 518-527.

9. de Villiers E, Bernard H, Fauquet C, Broker T, zur Hausen H (2004) Classification of papillomaviruses. Virology 324: 17- 27.

10. Munoz N, Bosch FX, Castellsague X, Diaz M, De Sanjose S, et al. (2004) Against which human papillomavirus types shall we vaccinate and screen? The international perspective. Int J Cancer 111(2): 278-285.

11. Smith JS, Lindsay L, Hoots B, Keys J, Franceschi S, et al. (2007). Human papillomavirus type distribution in invasive cervical cancer and highgrade cervical lesions: a meta-analysis update. Int J Cancer 121(3): 621-632.

12. De Sanjose S, Quint WG, Alemany L, Geraets DT, Klaustermeier JE, et al. (2010) Retrospective International Survey and HPV Time Trends Study Group. Human papillomavirus genotype attribution in invasive cervical cancer: a retrospective cross-sectional worldwide study. Lancet Oncol 11(11): 1048-1056.

13. Saslow D, Solomon D, Lawson H W, Killackey M, Kulasingam SL, et al. (2012) ACS-ASCCP-ASCP Cervical Cancer Guideline Committee. American Cancer Society, American Society for Colposcopy and Cervical Pathology, and American Society for Clinical Pathology screening guidelines for the prevention and early detection of cervical cancer. CA Cancer J Clin 62(3): 147-172.

14. Trottier H, Franco EL (2006) Human papillomavirus and cervical cancer: burden of illness and basis for prevention. Am J Manag Care 12: S462-S472.

15. Franco EL, Cuzick J (2008) Cervical cancer screening following prophylactic human papillomavirus vaccination. Vaccine 26: A16-A23.

16. No JH, Kim MK, Jeon YT, Kim YB, Song YS (2011) Human papillomavirus vaccine: widening the scope for cancer prevention. Mol Carcinog 50(4): 244-253.
17. Sanjose DS, Almirall R, Lloveras B, Font R, Diaz M, et al. (2003) Cervical human papillomavirus infection in the female population in Barcelona, Spain. Sex Transm Dis 30(10): 788-793.

18. Gonzalez C, Ortiz M, Canals J, Munoz L, Jarrin I, et al. (2006) Higher prevalence of human papillomavirus infection in migrant women from Latin America in Spain. Sex Transm Infect 82(3): 260-262.

19. Bernal M, Burillo I, Mayordomo JI, Moros M, Benito R, et al. (2008) Human papillomavirus (HPV) infection and intraepithelial neoplasia and invasive cancer of the uterine cervix: a case-control study in Zaragoza, Spain. Infect Agent Cancer 3: 8

20. Martorell M, Garcia-Garcia J A, Ortiz C, Perez-Valles A, Calabuig C, et al. (2010). Prevalence and distribution of human papillomavirus findings in swab specimens from gynaecology clinics of the east coast of Spain. Scand J Infect Dis 42(6-7): 549-553.

21. Brismar-Wendel S, Froberg M, Hjerpe A, Andersson S, Johansson, B (2009) Age-specific prevalence of HPV genotypes in cervical cytology samples with equivocal or low-grade lesions. Br J Cancer 101(3): 511517.

22. Gonçalves MA, Massad E, Burattini MN, Villa LL (1999) Relationship between human papillomavirus (HPV) genotyping and genital neoplasia in HIV-positive patients of Santos City, Sao Paulo, Brazil. Int J STD AIDS 10: 803-807.

23. Sjoeborg KD, Trope A, Lie AK, Jonassen CM, Steinbakk M, et al. (2010) HPV genotype distribution according to severity of cervical neoplasia. Gynecol Oncol 118(1): 29-34.

24. Ho GY, Bierman R, Beardsley L, Chang CJ, Burk RD (1998) Natural history of cervicovaginal papillomavirus infection in young women. $\mathrm{N}$ Engl J Med 338(7): 423-428.

25. Sellors JW, Karwalajtys TL, Kaczorowski J, Mahony JB, Lytwyn A, et al. (2003) Survey of HPV in Ontario Women Group. Incidence, clearance and predictors of human papillomavirus infection in women. CMAJ 168: 421-425.

26. de Sanjose S, Diaz M, Castellsague X, Clifford G, Bruni L, et al. (2007) Worldwide prevalence and genotype distribution of cervical human papillomavirus DNA in women with normal cytology: a meta-analysis. Lancet Infect Dis 7: 453-459.

27. Al-Awadhi R, Chehadeh W, Jaragh M, Al-Shaheen A, Sharma P, et al. (2011) Distribution of human papillomavirus among women with abnormal cervical cytology in Kuwait. Diagn Cytopathol 41(2): 107114

28. Ibanez R, Moreno-Crespi J, Sarda M, Autonell J, Fibla M, et al. (2012) Prediction of cervical intraepithelial neoplasia grade $2+(\mathrm{CIN} 2+)$ using HPV DNA testing after a diagnosis of atypical squamous cell of undetermined significance (ASC-US) in Catalonia, Spain. BMC Infect Dis 26: $12-25$

29. Toro de Mendez M, Llombart Bosch A (2009) Detection and genotyping of human papillomavirus DNA using polymerase chain reaction short PCR fragment 10-line probe assay in abnormal Papanicolaou-stained cervicovaginal smears. Acta Cytol 53: 540-547.

30. Toro de Mendez M, Ferrandez Izquierdo A(2011) Detection of human papilloma virus (HPV) in liquid-based cervical samples. Correlation with protein p16INK4a expression. Invest Clin 52(1): 3-14.

31. Mendez F, Munoz N, Posso H, Molano M, Moreno V, van den Brule AJ, et al. (2005) Instituto Nacional de Cancerologia Human Papillomavirus Study Group. Cervical coinfection with human papillomavirus (HPV) types and possible implications for the prevention of cervical cancer by HPV vaccines. J Infect Dis. 192(7): 1158-1165. 
32. Evans MF, Adamson CS, Schned LM, St John TL, Leiman G, et al. (2010) HPV is detectable in virtually all abnormal cervical cytology samples after reinvestigation of HPV negatives with multiple alternative PCR tests. Diagn Mol Pathol. 19(3): 144-150.

33. Roura E, Iftner T, Vidart JA, Kjaer SK, Bosch FX, et al. (2012) for the CLEOPATRE Spain Study Group. Predictors of human papillomavirus infection in women undergoing routine cervical cancer screening in Spain: the CLEOPATRE study. BMC Infect Dis. 12: 145.

34.Garcia-Garcia JA, Perez-Valles A, Martorell M, Gomez B, GomezCabrero D, et al. (2010) Distribution of human papillomavirus types in women from Valencia, Spain, with abnormal cytology. Acta Cytol 54(2): 159-164.

35. Delgado D, Marin JM, de Diego J, Guerra S, Gonzalez B, et al. (2011) Human papillomavirus (HPV) genotype distribution in women with abnormal cervical cytology in the Basque Country, Spain. Enferm Infecc Microbiol Clin 30: 230-235.

36. Otero-Motta AP, Ordonez JL, Gonzalez-Celador R, Rivas B, Macias Mdel C, et al. (2011) Prevalence of human papillomavirus genotypes in cytologic abnormalities from unvaccinated women living in northwestern Spain. APMIS 119(3): 204-215.

37. Galan-Sanchez F, Hernández-Menendez M, De Los Rios Hernandez MA Rodriguez-Iglesias M (2011) Performance of the New INNO-LiPA HPV extra to genotype human papillomavirus in cervical cell specimens. Acta Cytol 55(4): 341-343.

38. Selva L, Gonzalez-Bosquet E, Rodriguez-Plata MT, Esteva C, Sunol M, et al. (2009) Detection of human papillomavirus infection in women attending a colposcopy clinic. Diagn Microbiol Infect Dis 64(4): 416421.

39. Fife KH, Cramer HM, Schroeder JM, Brown DR (2001) Detection of multiple human papillomavirus types in the lower genital tract correlates with cervical dysplasia. J Med Virol 64(4): 550-559.

40. Clifford GM, Smith JS, Plummer M, Munoz N, Franceschi S (2003) Human papillomavirus types in invasive cervical cancer worldwide: a meta-analysis. Br J Cancer. 88(1): 63-73.

41. Clifford GM, Smith JS, Aguado T, Franceschi S (2003) Comparison of HPV type distribution in high-grade cervical lesions and cervical cancer: a meta-analysis. Br J Cancer 89(1):101-105.

42. Hindryckx P, Garcia A, Claeys P, Gonzalez C, Velasquez R, et al. (2006) Prevalence of high risk human papillomavirus types among Nicaraguan women with histological proved pre-neoplastic and neoplastic lesions of the cervix. Sex Transm Infect 82(4): 334-336.

43. Hariri S, Steinau M, Rinas A, Gargano JW, Ludema C, et al. (2012) HPV genotypes in high grade cervical lesions and invasive cervical carcinoma as detected by two commercial DNA assays, North Carolina, 2001-2006. PLoS One 7(3): e34044.

44. Rabelo-Santos SH, Zeferino L, Villa LL, Sobrinho JP, Amaral RG, et al. (2003) Human papillomavirus prevalence among women with cervical intraepithelial neoplasia III and invasive cervical cancer from Goiânia, Brazil. Mem Inst Oswaldo Cruz 98(2): 181-184.

45. Kjaer SK, van den Brule AJ, Paull G, Svare EI, Sherman ME, et al. (2002) Type specific persistence of high risk human papillomavirus (HPV) as indicator of high grade cervical squamous intraepithelial lesions in young women: population based prospective follow up study. BMJ 325(7364): 572.

46. Levi JE, Kleter B, Quint WG, Fink MC, Canto CL, et al. (2002) High prevalence of human papillomavirus (HPV) infections and high frequency of multiple HPV genotypes in human immunodeficiency virus-infected women in Brazil. J Clin Microbiol 40(9): 3341-3345.

47. Cuschieri KS, Cubie HA, Whitley MW, Seagar AL, Arends MJ, et al. (2004) Multiple high risk HPV infections are common in cervical neoplasia and young women in a cervical screening population. J Clin Pathol 57(1): 68-72.

48. Chaturvedi AK, Myers L, Hammons AF, Clark RA, Dunlap K, et al. (2005) Prevalence and clustering patterns of human papillomavirus genotypes in multiple infections. Cancer Epidemiol Biomarkers Prev 14: 2439-2445.

49. Andersson E, Karrberg C, Radberg T, Blomqvist L, Zetterqvist BM, et al. (2012) Type-dependent E6/E7 mRNA expression of single and multiple high-risk human papillomavirus infections in cervical neoplasia. J Clin Virol 54(1): 61-65.

50. ALTS study (2000) Human papillomavirus testing for triage of women with cytologic evidence of low-grade squamous intraepithelial lesions: baseline data from a randomized trial. The Atypical Squamous Cells of Undetermined Significance/Low-Grade Squamous Intraepithelial Lesions Triage Study (ALTS) Group. J Natl Cancer Inst 92(5): 397-402.

51. del Amo J, Gonzalez C, Losana J, Clavo P, Munoz L, et al. (2005) Influence of age and geographical origin in the prevalence of high risk human papillomavirus in migrant female sex workers in Spain. Sex Transm Infect 81(1): 79-84.

52. Sasagawa T, Basha W, Yamazaki H, Inoue M (2001) High-risk and multiple human papillomavirus infections associated with cervical abnormalities in Japanese women. Cancer Epidemiol Biomarkers Prev 10(1): 45-52.

53. Spinillo A, Dal Bello B, Gardella B, Roccio M, Dacco' MD, et al. (2009) Multiple human papillomavirus infection and high grade cervical intraepithelial neoplasia among women with cytological diagnosis of atypical squamous cells of undetermined significance or low grade squamous intraepithelial lesions. Gynecol Oncol 113(1): 115-119.

54.Song SH, Hong JH, Kwak SH, Lee JK, Kim MK (2012) Clinical performance assessment of five human papillomavirus DNA tests using liquid-based cytology samples. J Obstet Gynaecol Res 38(2): 408-414.

55. Schmitt M, Dondog B, Waterboer T, Pawlita M, Tommasino M, et al. (2010) Abundance of multiple high-risk human papillomavirus (HPV) infections found in cervical cells analyzed by use of an ultrasensitive HPV genotyping assay. J Clin Microbiol 48:143-149.

56. Soto-De Leon SC, Camargo M, Sanchez R, Leon S, Urquiza M, et al. (2009) Prevalence of infection with high-risk human papillomavirus in women in Colombia. Clin Microbiol Infect 15(1): 100-102.

57. Gomez-Roman JJ, Echevarria C, Salas S, González-Moran MA, PerezMies B, et al. (2009) A type-specific study of human papillomavirus prevalence in cervicovaginal samples in three different Spanish regions. APMIS 117(1): 22-27.

58. Clifford GM, Gallus S, Herrero R, Muñoz N, Snijders PJ, et al. (2005) IARC HPV Prevalence Surveys Study Group. Worldwide distribution of human papillomavirus types in cytologically normal women in the International Agency for Research on Cancer HPV prevalence surveys: a pooled analysis. Lancet 366: 991-998.

59. Li N, Franceschi S, Howell-Jones R, Snijders PJ, Clifford GM (2011) Human papillomavirus type distribution in 30,848 invasive cervical cancers worldwide: Variation by geographical region, histological type and year of publication. Int J Cancer 128(4): 927-935. 